\title{
Los Cabildos Insulares de Canarias
}

\author{
Manuel J. Sarmiento Acosta \\ Profesor Titular de Derecho Administrativo \\ Universidad de Las Palmas de Gran Canaria
}

SUMARIO: I. ORÍGENES Y EVOLUCIÓN HISTÓRICA. II. LA ISLA COMO ENTIDAD ARTICULADORA DEL SISTEMA. III. CONCEPTO Y NATURALEZA. IV. COMPOSICIÓN. V. ORGANIZACIÓN Y FUNCIONAMIENTO. VI. RÉGIMEN COMPETENCIAL. 1. En general. 2. Las competencias de los Cabildos como Corporaciones Locales. 3. Las competencias de los Cabildos como instituciones de la Comunidad Autónoma. 4. Breve referencia de las transferencias y delegaciones. VII. PATRIMONIO Y FINANCIACIÓN. VIII. EL DIFÍCIL ENCAJE INSTITUCIONAL DE LOS CABILDOS EN LA AUTONOMÍA CANARIA. BIBLIOGRAFÍA SUMARIA.

\section{ORÍGENES Y EVOLUCIÓN HISTÓRICA}

Los Cabildos Insulares son sin duda una de las instituciones más emblemáticas y representativas del Derecho Público de Canarias. Su origen más remoto hunde sus raíces en la misma incorporación de Canarias a la Corona de Castilla en el siglo xv, momento en el que se establece una organización, de igual carácter a la utilizada en Indias (BERMEJo GIRONÉs) ${ }^{1}$, por virtud de la cual se constituye en cada Isla un Concejo o Cabildo, con jurisdicción en toda la isla, considerada ésta como un municipio. Estos primitivos organismos, muy diferentes, como es lógico imaginar, a los actuales Cabildos, son cuerpos gestores configurados de acuerdo con los dogmas y principios imperantes en la época; algo que es preciso tener en cuenta para comprender cabalmente tanto su composición (escribanos, fieles ejecutores, alguaciles, etc.) como sus competencias para actuar en las distintas ramas de gestión - se configuraron, por ejemplo, como Tribunales de apelación hasta cierta cuantía en el orden civil-, y hasta su misma dependencia del Consejo de Castilla ${ }^{2}$.

Hay que distinguir, sin embargo, los Cabildos de las llamadas Islas de Realengo de los de las Islas de señorío; y, a su vez, dentro de las primeras, Gran Canaria, que tenía fuero propio, otorgado por los Reyes Católi-

\footnotetext{
1 «Los Cabildos Insulares de Canarias», en Voz de la Nueva Enciclopedia Jurídica Seix, Mancomunidades de Las Palmas y Santa Cruz de Tenerife, 1952, p. 17

${ }^{2}$ Cfr. L. DE la Rosa Olivera, Evolución del régimen local en las Islas Canarias, Madrid 1946, in totum. También es de interés, M. Velázquez CABRERA, Resumen histórico documentado de la autonomía de Canarias, Las Palmas, 1973
} 
cos el 20 de diciembre de 1494, de Tenerife y La Palma, que carecían de él. Aunque los datos que han llegado hasta nuestros días son incompletos e insuficientes, $y$, por lo tanto, es preciso ser prudente a la hora de hacer afirmaciones excesivamente rotundas, se puede apreciar cierta independencia en el desarrollo de las actividades de los Cabildos de las islas de señorío, a pesar, incluso, de que el nombramiento y relevo de los cargos del mencionado organismo era realizado libremente por los señores. Por su parte, los de las Islas de Realengo gozaban de mayor independencia y sirvieron de modelo para los de las Islas de señorío, si bien es evidente que los conceptos de «independencia» o «autonomía» hay que encuadrarlos en la época, sin caer en el error de valorarlos conforme a una interpretación contemporánea de la autonomía local.

Los Cabildos funcionan a lo largo del Antiguo Régimen, y sufren distintas vicisitudes, algunas de las cuales suponen la reducción de su ámbito competencial, como acontece con la constitución de nuevas instituciones, como la Audiencia de Canarias y la Capitanía General. Con la aprobación de la Constitución de Cádiz de 1812 (art. 11), se auspicia una nueva organización administrativa local, que, tras diversos episodios históricos, protagonizados por Fernando VII fundamentalmente, se plasma en el importante Real Decreto de Javier de Burgos, de 30 de noviembre de 1833, que en Canarias supone el establecimiento de una única provincia con capital en Santa Cruz de Tenerife, y el surgimiento y la acentuación de lo que se ha dado en llamar «pleito insular» (Guimerá PerazA) ${ }^{3}$, que durante todo el siglo XIX y gran parte del xx va a condicionar de forma negativa la actividad política y administrativa de la región. En este contexto, en 1836 desaparecen los antiguos Cabildos, y se implanta y desarrolla una organización administrativa, siguiendo patrones uniformistas, que produce la constitución de los Ayuntamientos constitucionales y de la Diputación Provincial como órgano de gobierno y administración de la recién creada provincia; organización que generará bastantes conflictos, por las posturas muy encontradas de Gran Canaria y Tenerife. Esta pugna desembocó, primero, en la «recreación» de los Cabildos Insulares, por medio de la Ley de 11 de julio de 1912, con un carácter bien distinto de los antiguos, y, en segundo término, en la escisión del Archipiélago Canario en dos provincias, por virtud del Real Decreto de 21 de septiembre de 1927.

Con el establecimiento de los Cabildos se inicia una nueva etapa en la que la singularidad de Canarias es tratada con más rigor y eficacia. La

${ }^{3}$ El pleito insular (1808-1036), Santa Cruz de Tenerife, 1976 
constitución efectiva fue, no obstante, distinta en cada Isla, ya que si los de Gran Canaria y Tenerife se constituyeron relativamente pronto, en 1913, y comenzaron a funcionar con regularidad, al igual que el de La Palma, no sucedió lo mismo con el de El Hierro, que no se constituyó hasta el año 1925. De forma paralela, la Diputación Provincial se debilita de manera considerable, de tal suerte que, mientras los Cabildos se fortalecen y cobran un auge inusitado absorbiendo parte de los servicios que la Diputación prestaba, ésta se convierte en un organismo sin apenas trascendencia. Por eso, el Estatuto provincial de 1925 la suprime y refuerza la posición de los Cabildos, asignándoles los derechos y obligaciones que el propio texto estatutario atribuía a las Diputaciones provinciales de la Península. Asimismo, el Estatuto provincial estableció la obligatoriedad de una Mancomunidad interinsular, formada por los representantes de todos los Cabildos, que tenía como principal objetivo la representación de la provincia. Se admitían, además, las mancomunidades voluntarias. Y, con la división provincial, obviamente, se prescribe la obligatoriedad de dos Mancomunidades Interprovinciales, que lejos de asumir competencias provinciales, ejercen funciones más bien residuales (arts. 189-191 del Estatuto).

Durante la II República y el régimen dictatorial franquista, la orientación sobre esta materia sigue el mismo sentido; es decir, la de potenciar la operatividad de los Cabildos, y relegar a las Mancomunidades a un papel muy secundario. Es necesario resaltar que la Constitución de 1931 (art. 10) constitucionaliza los Cabildos de forma detallada y respetuosa con su condición (Hernández Bravo de Laguna) ${ }^{4}$, y, en la etapa política que surge tras la finalización de la guerra civil, experimentan un incremento notable de sus atribuciones y desarrollan un papel de primer orden, lo cual guarda estrecha conexión con la buena cobertura económica que también tenían. Y, en el régimen preautonómico, iniciado en la primavera de 1978, comienza el proceso de vaciamiento competencial de las Mancomunidades Provinciales Interinsulares, que se materializa con la aprobación del Estatuto de Autonomía por la Ley Orgánica 10/1982, de 10 de agosto (disposición transitoria séptima), que establece el traspaso a las instituciones de la Comunidad Autónoma de las competencias, medios y recursos de las Mancomunidades Provinciales Interinsulares (Decreto 107/1985, de 19 de abril).

En este contexto político y jurídico, los Cabildos se configuran como los organismos más adecuados para el gobierno y la administración de las

\footnotetext{
4 «La política local en Canarias: la experiencia de la Autonomía», en Jornadas sobre la situación actual de la Administración local en Canarias, Gobierno de Canarias, 1997, pp. 32 y 33.
} 
Islas, algo que ya se indica en la Constitución Española de 27 de diciembre de 1978 (art. 141.4), y que se patentiza de forma diáfana en el Estatuto de Autonomía, el cual, como veremos con más pormenor más adelante, les confiere una doble naturaleza (Corporaciones locales e instituciones de la Comunidad Autónoma).

\section{LA ISLA COMO ENTIDAD ARTICULADORA DEL SISTEMA ${ }^{5}$}

En el Ordenamiento jurídico vigente hay un reconocimiento explícito de la Isla como entidad vertebradora del sistema. Hay una clara conciencia en el legislador de que el Archipiélago Canario posee unos rasgos característicos singulares que impulsan a organizar las instituciones y establecer las regulaciones contando con el hecho insular.

Con independencia de lo que prevé la Carta Magna (arts. 69.3, 138.1,141.4 y 143.1), de la lectura del Estatuto de Autonomía de Canarias, en su nueva redacción de 1996, se extrae la conclusión de que para el legislador la Isla es la auténtica pieza clave del modelo [arts.1, párrafo 2; 5.2,c), 7, 8.2, 9.4, 12.4, 15.3, 22.2, 23, 29.4, 36, 38.3, 48, 50, 55.1, 56.1,c), $62.3,65$, y disposiciones transitoria primera, 2 y tercera]. Hay una insistencia sobre la entidad a lo largo de todo el Estatuto, si bien los preceptos que reflejan con mayor claridad la posición de las Islas son los artículos 8 y 23, al disponer que las Islas se configuran como elementos de la organización territorial de Canarias (art. 8), la cual se articula sobre las mismas (art. 23). Y en este contexto es sintomático que el referido artículo 23.1, que es producto de la Ley Orgánica 4/1996, no mencione ni a municipios ni a provincias. Nombra exclusivamente las Islas, de manera diferente a lo que disponía la primera redacción dada en 1982 al, entonces, artículo 22 del Estatuto, el cual configuraba como entes vertebradores de la Comunidad a las Islas y los municipios.

En principio, esta opción del legislador parece coherente con las circunstancias físicas que concurren en el territorio que aspira organizar, habida cuenta de que en el Archipiélago Canario la provincia no ha desempeñado un papel relevante, y han sido y son las Islas las auténticas instancias a través de las cuales se ha llevado a cabo la actividad administrativa. Así, conectando con lo que dispone el artículo 141.4 de la Norma Suprema, que reconoce, aunque sea de forma tangencial, la Isla como entidad

\footnotetext{
${ }^{5}$ M.J. SARmiento Acosta, Las competencias de los Cabildos Insulares, Las Palmas, 1993, pp. 100 y ss.
} 
local territorial, el Estatuto define la organización territorial de la mejor forma que pudo hacerlo, ya que la realidad insular y los problemas permanentes que condicionan el devenir del Archipiélago (costes superiores por la lejanía, pleito insular, relaciones entre Islas centrales y no centrales, etc.) aconsejaban la opción por esta alternativa, que es más congruente con los presupuestos determinantes de la organización. Y, aunque es verdad que las provincias canarias subsisten ${ }^{6}$, los órganos de expresión y representación de éstas, las Mancomunidades Provinciales Interinsulares (art. 41. 2, de la Ley 7/1985, de 2 de abril, reguladora de las bases del régimen local, LRBRL), integradas por los Presidentes de los Cabildos de las provincias correspondientes, carecen de verdadero protagonismo político e institucional.

Las Islas en cuanto elementos de la organización territorial de Canarias gozan de autonomía plena para el ejercicio de los intereses propios. También gozarán de autonomía para el ejercicio de las competencias que se les atribuyan en el marco que establece la Constitución y su legislación específica (art. 23.3, EACan.).

A las Islas les corresponde, asimismo, «el ejercicio de las funciones que les son reconocidas como propias, las que se les transfieran o deleguen por la Comunidad Autónoma, y la colaboración en el desarrollo y la ejecución de los acuerdos adoptados por el Gobierno Canario, en los términos que establezcan las leyes de su Parlamento. Las transferencias y delegaciones llevarán incorporados los medios económicos, materiales y personales que correspondan» (art. 23.4, EACan.).

\section{CONCEPTO Y NATURALEZA}

Los Cabildos son, simultáneamente, órganos de gobierno, administración y representación de las Islas e Instituciones de la Comunidad Autónoma (arts. 8.2 y 23, EACan; 41.1, LRBRL, y 5.2 de la Ley 14/1990, de 26 de julio, de Régimen Jurídico de las Administraciones Públicas de Canarias, LC). Pero básicamente son Corporaciones locales, cuya posición queda determinada por la legislación básica del Estado y por la que dicte la Comunidad Autónoma en desarrollo de aquélla (art. 5.3, LC). Así, tienen todas las potestades y características propias de las Corporaciones

\footnotetext{
${ }^{6}$ Vid. C. De La Concha Bergillos, «El régimen provincial de Canarias. Las Mancomunidades Provinciales Interinsulares», Revista Canaria de Administración Pública núm. 14, 1992, pp. 31 y ss. También L.P. Bourgon TinaO, «La naturaleza de la provincia en Canarias», Revista de Administración Pública núm. 100-102, vol. III, 1983, pp. 2113 y ss.
} 
locales (arts. 4 y 5, LRBRL), y están sometidos a los mismos principios que informan la actuación de éstas, es decir, eficacia, descentralización, desconcentración y coordinación, con sometimiento pleno a la ley y al Derecho (art. 6.1, LRBRL).

La calificación de estos organismos como Instituciones de la Comunidad Autónoma de Canarias se encuentra en el Estatuto de Autonomía (arts. 8.2 y 23), y está desarrollada en la conocida coloquialmente como «Ley de Cabildos» (Ley 14/1990, de 26 de julio, de Régimen Jurídico de las Administraciones Públicas de Canarias); y supone que gozan de una posición bifronte. En este extremo, el Consejo Consultivo de Canarias, en el Dictamen núm. 1/1985, de 31 de octubre, para tratar de ubicar, explicar y dar sentido a la nueva situación de los Cabildos, afirmó que el concepto de Comunidad Autónoma era dual, porque en unos casos tiene un sentido amplio que incluye a los Cabildos como «coadyuvantes estatutarios en la prosecución de sus fines», mientras que en otros tiene un sentido estricto; lo cual indica que los Cabildos no son propiamente instituciones de autogobierno, sino que el carácter institucional-comunitario se añade para otorgar a los Cabildos una nueva funcionalidad institucional en la Comunidad Autónoma, y que tiene su razón de ser última en la mejor gestión de los intereses canarios. Fruto de este carácter es la particular posición y las destacadas funciones que el propio Estatuto de Autonomía les asigna, como su participación en el Parlamento de Canarias a través de la Comisión General de Cabildos Insulares (art. 12.3, EACAn.), la iniciativa legislativa que tienen (art. 12.5, EACAn.) o la representación ordinaria del Gobierno y de la Administración autonómica en cada Isla (art. 23.5, EACAn). En conclusión, los Cabildos siguen siendo fundamentalmente Corporaciones locales que gobiernan, administran y representan a cada isla, y como tales se rigen por las normas que la LRBRL de 1985 contiene para regular la organización y funcionamiento de las Diputaciones Provinciales, asumiendo también, las competencias de éstas, sin perjuicio de las que les correspondan por su legislación específica (arts. 41.1, LRBRL y 5.3, LC), y sólo secundum quid son instituciones de la Comunidad Autónoma, con un carácter instrumental preordenado a insertar a los Cabildos en el entramado institucional de una Comunidad con unos rasgos tan singulares y complejos como la canaria.

\section{COMPOSICIÓN}

A diferencia de otras etapas en las que no ha sido así, en la actualidad los Cabildos tienen una composición plenamente democrática, pues los 
Consejeros son elegidos por los ciudadanos de la respectiva Isla ${ }^{7}$. El número de Consejeros varía en función de la población de derecho de cada Isla. Es preciso advertir de que, aunque los Cabildos se rigen en cuanto a su organización y funcionamiento por las normas previstas para las Diputaciones provinciales (art. 41.1 en relación con el art. 36, LRBRL), la elección de los Consejeros es netamente diferente a la de los Diputados provinciales, algo que es observable desde la Ley 39/1978, de 17 de julio, de Elecciones Locales. La elección de los Consejeros es directa o de primer grado, y se encuentra regulada en el Título IV (art. 201) de la Ley Orgánica 5/1985, de 19 de junio, de Régimen Electoral General (LOREG); Ley que ha sufrido varias reformas, algunas de las cuales han afectado directamente a los Cabildos, como la operada por la Ley Orgánica 8/1991, de 13 de marzo, o la llevada a cabo por medio de la Ley Orgánica 8/1999, de 21 de abril. Conforme a estas normas, cada Isla constituye una circunscripción electoral, y los Consejeros son elegidos por sufragio universal, directo y secreto, en listas cerradas y bloqueadas, en una urna distinta a la destinada a la votación de Concejales. El mandato es de cuatro años, contado a partir de la fecha de su elección, y la atribución de escaños se realiza siguiendo el sistema proporcional corregido D'Hondt, con una barrera electoral de exclusión del 5 por 100. La LOREG determina el número de Consejeros de acuerdo con la siguiente escala:

Hasta 10.000 residentes

De 10.001 a 20.000 residentes

De 20.001 a 50.000 residentes

De 50.001 a 100.000 residentes

De 100.001 en adelante
11 Consejeros

13 Consejeros

17 Consejeros

21 Consejeros

1 Consejero por cada 100.000 residentes o fracción, añadiéndose dose uno más cuando el resultado sea número par.

Una vez celebradas las elecciones locales, la constitución de las Corporaciones insulares difiere de la de las Diputaciones Provinciales de la Península, ya que se establece que la constitución se efectuará treinta días después de la celebración de las elecciones, en sesión que presidirá una

\footnotetext{
${ }^{7}$ J.A. GarCía Rojas, «El régimen electoral de los Cabildos Insulares», en el volumen coordinado por J.J. RodRíGuez y él mismo, El régimen especial político-administrativo de Canarias. Las singularidades, Madrid-Barcelona, 1999, pp. 173 y ss. Y, del mismo autor, «Peculiaridades electorales, organizativas, relacionales y reaccionales de los Cabildos Insulares Canarios», Actualidad Administrativa num. 38, 2002, in totum
} 
Mesa de Edad, integrada por los elegidos de mayor y menor edad presentes en el acto, actuando como Secretario el que lo sea de la Corporación (art. 195, LOREG.); se comprueban las credenciales que acreditan la condición de Consejero y se declarará constituida la Corporación si concurre la mayoría absoluta de los miembros electos. En caso contrario, se celebra una sesión dos días después, quedando constituido el Cabildo cualquiera que sea el número de Consejeros.

El Presidente del Cabildo tiene, asimismo, un proceso de elección particular y distinto al del Alcalde o al del Presidente de la Diputación Provincial ${ }^{8}$. En una fórmula original dentro del sistema electoral español, se establece que la condición de Presidente se adquiere «por ministerio de la ley», como afirmó hace algunos años la Sentencia de la Sala de lo Contencioso-Administrativo de Las Palmas del Tribunal Superior de Justicia de Canarias (STSJC), de 18 de diciembre de 1995, y no, por consiguiente, por elección de los Consejeros ni de los ciudadanos. El artículo 201.5,LOREG dispone: «Será Presidente del Cabildo Insular el candidato primero de la lista más votada en la circunscripción insular». La STS de 26 de mayo de 1997, que rectificó en casación la STSJC que se acaba de indicar, ha declarado expresamente el carácter híbrido del cargo. Por lo demás, el Presidente puede perder su condición por las causas habituales (dimisión, expiración del mandato, etc.), y, además, por no superar una moción de censura o una cuestión de confianza. Respecto de la primera, una vez que se superaron las dudas que se mantuvieron sobre la posibilidad o no de plantearla por virtud de la modificación de la LOREG, hecha por la Ley Orgánica 8/1991, es necesario advertir que el Presidente puede ser destituido de su cargo mediante la moción de censura, que se desarrollará de acuerdo con lo dispuesto en el artículo 197, LOREG para el Alcalde, salvo en lo relativo al candidato alternativo, porque en todo caso, y en coherencia con la forma de elección del Presidente, deberán ser los Consejeros que encabecen las listas respectivas, y para poder triunfar se requiere mayoría absoluta.

Es importante indicar que a raíz de la reforma de la LOREG realizada por la Ley Orgánica 8/1999, de 21 de abril, se establece, para hacer frente a una serie de comportamientos fraudulentos que la práctica ha ido propiciando ${ }^{9}$, la convocatoria automática del Pleno para las doce horas del

\footnotetext{
8 J.J. SuAY Rincón, «Régimen electoral. Especificidades de las Diputaciones Provinciales y Cabildos Insulares», en Estudios Jurídicos y territoriales sobre Canarias, Islas Canarias, 2001, pp. 268 y ss.

${ }^{9}$ Una relación sintética de jurisprudencia, reveladora de ciertos comportamientos y corruptelas, la podemos encontrar en el trabajo de R. FERnÁNDEZ VALVERDE, «Control jurisdiccional de la Admi-
} 
décimo día hábil siguiente al de su registro. La citada Ley Orgánica 8/1999 también ha establecido otra novedad de relieve: la posibilidad de que el Presidente del Cabildo - al igual que, en sus respectivas Corporaciones, el Alcalde y el Presidente de la Diputación-, pueda plantear al Pleno una cuestión de confianza, vinculada a la aprobación o modificación de cualquiera de los siguientes asuntos: a) los presupuestos anuales, b) el reglamento orgánico, c) las ordenanzas fiscales, d) la aprobación que ponga fin a la tramitación de los instrumentos de planeamiento general de ámbito insular, para lo cual se requiere el quorum de votación exigido en la LRBRL para cada uno de ellos. La votación se efectuará, en todo caso, mediante el sistema nominal de llamamiento público; y, en caso de no obtenerse la confianza, el nuevo Presidente del Cabildo se elegirá de acuerdo con el sistema previsto en el artículo 197 bis para los Alcaldes de municipios de más de 250 habitantes.

\section{ORGANIZACIÓN Y FUNCIONAMIENTO}

La organización y el funcionamiento de los Cabildos vienen determinadas por la legislación básica estatal, las normas que dicta la Comunidad Autónoma en el ámbito de sus competencias y las que, en ejercicio de la potestad organizatoria - Reglamentos orgánicos-, puedan elaborar y aprobar los propios Cabildos ${ }^{10}$.

La legislación básica estatal ha seguido la tradicional tendencia de equiparar los Cabildos con las Diputaciones provinciales, como se deduce de la lectura del artículo 41.1, LRBRL: "Los Cabildos, como órganos de gobierno, administración y representación de cada Isla, se rigen por las normas de esta ley que regulan la organización y funcionamiento de las Diputaciones provinciales...». De acuerdo con la remisión que el precepto ordena, la regulación está contenida en los artículos 32 y siguientes de la LRBRL, así como en el desarrollo reglamentario establecido en el Real Decreto 2568/1986, de 28 de noviembre, que aprueba el Reglamento de Organización, Funcionamiento y Régimen jurídico de las Entidades Locales (ROF), el cual se aplica mientras no se apruebe legislación autonómica sobre la materia o disponga de reglamento orgánico. Así, conforme a estos preceptos, los Cabildos disponen de una organización necesaria, que

nistración Local», en Jornadas sobre la situación actual de la Administración Local en Canarias, Gobierno de Canarias, 1997, pp. 256-263

${ }^{10}$ Vid. M.J. SARmiento Acosta, «La posición ordinamental de los Reglamentos orgánicos de las Entidades locales tras la Sentencia 214/1989, de 21 de diciembre, del Tribunal Constitucional», REALA núm. 252, 1991, pp. 973-978 
comprende al Presidente, los Vicepresidentes, la Comisión de Gobierno y el Pleno (arts. 32.1, LRBRL y 55, ROF), y una organización complementaria. En este sentido, el artículo 32.2) prescribe que existirán en todas las Diputaciones (es decir, Cabildos) «órganos que tengan por objeto el estudio, informe o consulta de los asuntos que han de ser sometidos a la decisión del Pleno, así como el seguimiento de la gestión del Presidente, la Comisión de Gobierno y los Consejeros que ostenten delegaciones, siempre que la respectiva legislación autonómica no prevea una forma organizativa distinta en este ámbito y sin perjuicio de las competencias de control que corresponden al Pleno».

La organización complementaria viene definida fundamentalmente por la legislación autonómica y por el mismo Cabildo a través de su Reglamento orgánico. Así, la disposición adicional quinta de la LC, en una de sus más significativas aportaciones, establece que «para garantizar la eficacia en la prestación de las nuevas funciones asumidas en virtud de esta ley, los Cabildos Insulares, mediante la modificación de sus Reglamentos orgánicos y relaciones de puestos de trabajo, adecuarán sus estructuras administrativas. A tal fin, los Cabildos Insulares podrán crear órganos unipersonales, bien de carácter administrativo cuya funciones serán ejercidas por funcionarios de carrera, como los directores de servicio, bien de carácter político, cuyo titular deberá ser un Consejero electo». Por otro lado, la mayoría de los Cabildos ya han aprobado sus respectivos Reglamentos orgánicos [art. 4.1,a), LRBRL, y 4.1,a), ROF], de cuya regulación son destacables figuras como la Junta de Portavoces o los Directores Insulares de área.

En cuanto al funcionamiento, es claro que deberá estar inspirado en el principio democrático y participativo; $\mathrm{y}$, por tanto, tiene especial trascendencia el funcionamiento colegiado, lo que implica que muchos acuerdos deberán ser adoptados preceptivamente por los órganos colegiados (art. 33, LRBRL). Debe tenerse en cuenta que, en este punto, la Ley 30/1992, de 26 de noviembre, de Régimen Jurídico de las Administraciones Públicas y del Procedimiento Administrativo Común, establece en su disposición adicional primera que «las disposiciones del Capítulo II del Título II de la presente Ley (esto es, los arts. 22 a 27, relativos a los órganos colegiados) no serán de aplicación al Pleno y, en su caso, Comisión de Gobierno de las Entidades Locales, a los Órganos Colegiados del Gobierno de la nación y a los Órganos de Gobierno de las Comunidades Autónomas» Por lo demás, la LRBRL (Título V, «Disposiciones comunes a las Entidades locales», arts. 46 a 78), fija los criterios básicos de funcionamiento que deben seguirse en cualquier caso; criterios que han sido refor- 
mados en 1999 como consecuencia del denominado «Pacto Local», en orden a evitar un conjunto de prácticas de claro carácter fraudulento, que entorpecen y perturban de forma grave el funcionamiento de las Corporaciones Locales (no convocar el Pleno adrede, dificultar la labor de control de los miembros de la Corporación, etc.). Así, la Ley 11/1999, de 21 de abril, modificó la LRBRL, y, en la cuestión que tratamos, ha impuesto la celebración de una sesión ordinaria cada mes como mínimo (art. 46, LRBRL), y, además, la LOREG, en su nueva redacción, impone la convocatoria automática cuando se presenta una moción de censura, puesto que una vez que se presenta el documento correspondiente en el Registro General de la Corporación por cualquiera de los firmantes de la moción, queda «automáticamente convocado (el Pleno) para las doce horas del décimo día hábil siguiente al de su Registro», y el Secretario de la Corporación deberá remitir notificación indicativa de tal circunstancia a todos los miembros de la misma en el plazo máximo de un día, a contar desde la presentación del documento en el Registro, a los efectos de su asistencia a la sesión, especificando la fecha y hora de la misma (arts. 201.7, y 197, LOREG, modificada por la Ley Orgánica 8/1999).

Los acuerdos se adoptan, por regla general, por mayoría simple (mayoría de votos afirmativos) (art. 47.1, LRBRL) de los miembros presentes, siempre que el órgano esté válidamente constituido y la convocatoria se haya efectuado como impone la ley, si bien existen casos en los que se exigen mayorías cualificadas, que suponen, como es natural, un quórum reforzado. Así sucede, por ejemplo, cuando se aprueba un Reglamento orgánico, cuando se acuerda la transferencia de funciones o actividades a otras Administraciones públicas, así como la aceptación de las delegaciones o encomiendas de gestión realizadas por otras Administraciones, salvo que por ley se imponga obligatoriamente, o con la imposición y ordenación de los recursos propios de carácter tributario, etc. (art. 47.2 y 3, LRBRL).

La configuración de la organización y el funcionamiento de los Cabildos de forma idéntica a la de las Diputaciones provinciales es una regla tradicional en nuestro Derecho local. Sin embargo, es evidente que las posiciones de los Cabildos y las Diputaciones son diferentes, de acuerdo con lo previsto en nuestro Ordenamiento jurídico. Se ha advertido que los Cabildos son, además de Corporaciones Locales, Instituciones de la Comunidad Autónoma (arts. 8.2 y 23, EACan.), y ello comporta un claro protagonismo en la vida política y administrativa del Archipiélago, de forma distinta a lo que ha sucedido y sucede en otras Comunidades Autónomas, donde bastantes Diputaciones no alcanzan excesiva signifi- 
cación ${ }^{11}$. Es necesario destacar, por otra parte, que en otra Comunidad Autónoma con algunos rasgos muy similares a la canaria, como es la de las Islas Baleares, los Consejos Insulares son calificados como instituciones de la Comunidad ${ }^{12}$; en concreto, y aparte de las Sentencias dictadas por la Sala de lo Contencioso-Administrativo del Tribunal Superior de Justicia de las Islas Baleares (v. gr.: Sentencias de 13 de julio de 1991 ó 26 de febrero de 1992), el Tribunal Supremo, en Sentencia de 26 de junio de 1998, ha proclamado la doble naturaleza de los Consejos Insulares, «tienen — dice el Alto Tribunal-, la doble naturaleza de órganos representativos y de gobierno y administración de una entidad local y simultáneamente el de órganos autonómicos». Y tienen, por lo tanto, una organización que difiere diáfanamente de las Diputaciones y de los Cabildos. Es palmario que Consejos Insulares y Cabildos no se pueden homologar, toda vez que entre ellos hay notorias divergencias (piénsese que los Consejos Insulares se integran por los diputados elegidos para el Parlamento autonómico), pero también lo es que los Cabildos quizá necesiten una organización y un funcionamiento que se ajuste más a su nueva consideración de instituciones autonómicas, y, sobre todo, al volumen amplio de funciones que ejercen. Por este razón la Ley Orgánica 4/1996 ha establecido una nueva redacción del artículo 23.3 del EACan, que auspicia un nuevo enfoque sobre este importante extremo, pues dispone que «su organización y funcionamiento se regirá por una Ley aprobada por mayoría absoluta del Parlamento de Canarias en el marco de la Constitución».

\section{RÉGIMEN COMPETENCIAL}

\section{En general}

Los Cabildos ejercen un conjunto de competencias que los convierte en unas Administraciones Públicas de enorme trascendencia en la vida administrativa de las Islas Canarias. Es más, se puede afirmar que la atribución y traslación de competencias a estas Corporaciones ha supuesto una de las manifestaciones más emblemáticas del proceso descentralizador hacia las Corporaciones Locales que se ha desarrollado en España en los últimos

\footnotetext{
11 Vid. E. García de EnTERríA, «La provincia en la Constitución», en el volumen colectivo La provincia en el sistema constitucional, dirigido por R. Gómez-Ferrer Morant, Madrid, 1991, pp. 15-17.

12 B. Colom Pastor Veinticinco años de Autonomía balear. Estudios jurídicos sobre el autogobierno (1997-2000), Madrid-Barcelona, 2001, pp. 125 y ss.
} 
veinte años. Ello ha comportado que, desde el inicio de la Autonomía Canaria, se tuviera plena conciencia de la necesidad de organizar este proceso como medio para hacer efectivos los principios constitucionales (art. 103.1) y estatutarios (art. 22, EACan.) que se propugnan, y que constituyen el «nervio» de la organización administrativa que se implanta y desarrolla en el llamado «Estado autonómico». Esta conciencia se detecta, por ejemplo, en el preámbulo de la primera «Ley de Cabildos», es decir, la Ley 8/1986, de 18 de noviembre, de Régimen Jurídico de las Administraciones Públicas de Canarias ( «La Ley pretende construir un ordenamiento coherente que refleje los principios políticos expuestos, afronta la regulación de los Cabildos Insulares en su doble consideración»), o en los artículos 6.2 y 8 . Y, como es evidente, en el artículo 8.2 de la segunda «Ley de Cabildos», la Ley 14/1990, de 26 de julio, de Régimen Jurídico de las Administraciones Públicas de Canarias, que derogó la anterior, que dice: «El Parlamento de Canarias, en ejercicio de su potestad legislativa, atribuirá competencias a las diferentes Administraciones por cualquiera de los títulos y con ajuste a los principios y las reglas establecidas en el Estatuto de Autonomía de Canarias, en la ley reguladora de las Bases del Régimen Local y en la presente Ley».

Y es obvio que para articular la descentralización se impone atribuir y trasladar, mediante las transferencias ${ }^{13}$, delegaciones y encomiendas de la gestión, competencias a las Corporaciones Insulares, algo que se ha efectuado desde la segunda mitad de los años ochenta del pasado siglo.

Podemos así distinguir las competencias que los Cabildos Insulares tienen en su consideración de Corporaciones Locales, y las que desarrollan en su nueva calidad de Instituciones de la Comunidad Autónoma de Canarias.

\section{Las competencias de los Cabildos Insulares como Corporaciones Locales}

Estas competencias vienen determinadas por equiparación, como ya es tradicional en el Derecho local español, a las que tienen las Diputaciones Provinciales (art. 41.1, en relación con el art. 36, ambos de la LRBRL), si bien el Parlamento de Canarias asume también un importante papel, ya que está legitimado para conferir poderes o funciones a los Cabildos en el marco de las competencias asumidas.

\footnotetext{
13 R. Alcázar Crevillén, «Las transferencias de competencias de la Comunidad Autónoma de Canarias a los Cabildos Insulares», Revista Canaria de Administración Pública núm. 0, 1989, pp. $11-26$
} 
La Ley 14/1990, de 26 de julio, de Régimen Jurídico de las Administraciones Públicas de Canarias, modificada por la Ley 4/1996, de 5 de noviembre, y, más recientemente, por la Ley 8/2001, de 3 de diciembre, siguiendo el criterio estatutario (art. 23), establece que los Cabildos tienen atribuido el gobierno, la administración y representación de la Isla, y gozan de plena autonomía para el ejercicio de sus competencias propias (art. 41). Y son competencias propias de los Cabildos, además de las reconocidas en el artículo 5 de la Ley de 11 de julio de 1912, de Régimen del Archipiélago Canario, las que les atribuyan con tal carácter, de acuerdo con lo dispuesto en la LRBRL, y en las Leyes reguladoras de los distintos sectores de la acción pública (art. 42, LC). Estas competencias propias se ejercen en régimen de autonomía y bajo la propia responsabilidad de los Cabildos (art. 7.2, LRBRL), y constituyen el núcleo duro de la autonomía que constitucionalmente tienen garantizada (arts. 137 y 141.4, CE). Sólo pueden ser determinadas por ley (art. 7.1, LRBRL), y no pueden ser objeto de controles genéricos e indeterminados, sino de controles específicos. Con carácter general, se puede decir que estas competencias se atribuyen por las distintas Leyes sectoriales, esto es, aquellas que regulan los diversos sectores o áreas de la acción pública (urbanismo, vivienda, turismo, aguas, patrimonio histórico-artístico, sanidad, etc.), que los legisladores estatal o autonómico dicten en el ejercicio de sus competencias, y en el ámbito definido por el denominado «bloque de constitucionalidad» (art. 2.1, LRBRL, STC 214/1989, de 21 de diciembre, y STS de 23 de mayo de 1997). Las competencias propias tienen una gran trascendencia, porque deberán concretar un poder o capacidad efectiva para que los Cabildos, en su faceta de Corporaciones Locales, ordenen y gestionen una parte importante de los asuntos públicos insulares, como establece el artículo 3.1 de la Carta Europea de Autonomía Local.

Pero, junto con las competencias propias, las Corporaciones insulares pueden ejercer competencias delegadas, que se desarrollan en los términos establecidos en la delegación y se someten a unos controles más rigurosos por parte de la Administración delegante, que, en su caso, pueden llegar a la revocación pura y simple de la delegación (art. 55.2, LC). Así, es posible aplicarles técnicas de dirección y control de oportunidad, que, en todo caso, deberán respetar la potestad autoorganizatoria de los servicios de los Cabildos (arts. 7.3 y 37, LRBRL). Asimismo, pueden ejercer competencias transferidas, que, según el párrafo segundo del artículo 42, LC, tienen idéntico carácter que las propias (sic), lo cual no es del todo cierto, ya que caben controles que no son aplicables a las competencias propias [arts. 46.2 y 50,b) y c), LC]. Por otro lado, es posible también que desarrollen funciones encomendadas (arts. 22.3, EACan, 5.1, Ley 
12/1983, de 14, del Proceso Autonómico, 8 y 37.1, LRBRL), sometidas a un control mucho más riguroso ${ }^{14}$, pues en este caso hay una verdadera sujeción jerárquica. Por ello se suele hablar en este supuesto de un «mero préstamo de órganos», en virtud del cual el Cabildo es un simple instrumento para la realización de determinadas actividades, sin capacidad de decisión ni responsabilidad propias.

\section{Competencias de los Cabildos Insulares como instituciones de la Comunidad Autónoma}

Una de las aportaciones más significativas del Estatuto de Autonomía y de la legislación aprobada por el Parlamento de Canarias a la nueva posición de los Cabildos es sin duda su calificación como instituciones de la Comunidad Autónoma ${ }^{15}$, en un deseo de insertar las Corporaciones Insulares en el organigrama de la Comunidad, y, por tanto, aprovechar la experiencia y solidez de aquéllas en orden a gestionar y administrar los asuntos insulares. Pues bien, para que esta nueva categoría tenga algún sentido debe tener una traducción real y efectiva en la faceta competencial; de lo contrario no pasaría de ser mera retórica. Por ello, en coherencia con la elevación a instituciones de la Comunidad, el EACan atribuye un conjunto de competencias que dan contenido al carácter institucional de las mencionadas Corporaciones. Así se establece que:

1..$\left.^{\circ}\right)$ Ostentan la iniciativa legislativa en el Parlamento autonómico [arts. 12.5, EACan, y 36.2, a) y 37 a 39, LC]. Esta iniciativa no prejuzga la titularidad del poder legislativo, que lógicamente es del Parlamento Canario, y puede versar sobre cualquier materia sobre la que pueda pronunciarse legislativamente la Comunidad Autónoma. El procedimiento comienza con la aprobación de la proposición por la mayoría absoluta del número legal de miembros del Cabildo; el Secretario de la Corporación expide certificación del cumplimiento de los requisitos correspondientes, y luego se envía a la Cámara regional.

\footnotetext{
14 A. Gallego Anabitarte, junto con J.A. Chinchilla, A. De Marcos y B. Rodríguez-Chávez, Conceptos y principios fundamentales del Derecho de Organización, Madrid-Barcelona, 2000, pp. $108 \mathrm{y}$ ss.

15 M.J. SARmiento Acosta, «Comentarios al artículo 22», en el volumen colectivo Comentarios al Estatuto de Autonomía de Canarias, dirigido por J. VArona Gómez-AcEdo, Madrid, 1996, pp. 203212. Puede verse, asimismo, J.F. LóPez Agullar, «Los Cabildos Insulares en el Derecho Canario», en el volumen colectivo La Provincia en el Estado de las Autonomías, Madrid, 1996, particularmente, pp. 350 y 351; y J.A. García Rojas, S. Peraza y J.E. García, «Las relaciones entre la Comunidad Autónoma de Canarias y los gobiernos locales canarios: la opción por los Cabildos Insulares», Actualidad Administrativa núm. 4, 2001, pp. 85 y ss.
} 
Además, es importante destacar que, tras la reforma del EACan, llevada a cabo por la Ley Orgánica 4/1996, los Cabildos participan en el Parlamento a través de la Comisión General de Cabildos Insulares (art. 12.3, EACan) ${ }^{16}$. Comisión nueva y singular, que se perfila como un mecanismo de participación en la actividad parlamentaria, aunque sus funciones son meramente consultivas e informativas. El artículo 52.4 del Reglamento del Parlamento de Canarias dispone que: «Los Presidentes de los Cabildos asistirán, con voz a las sesiones de la Comisión, a cuyo fin serán convocados en la misma forma que los diputados miembros de ésta. Asimismo, podrán solicitar que se haga constar en el acta de la sesión su posición sobre los asuntos sometidos a votación».

Por otra parte, y relacionado con lo anterior, es preciso indicar que, en el ámbito del procedimiento de reforma del EACan, los Cabildos tienen una audiencia preceptiva, pero no vinculante, cuando la pretendida reforma «tuviera por objeto una alteración de los poderes de Canarias que afectara directamente a las Islas» (art. 65, EACan). Se trata de una audiencia de cierta importancia. El Consejo Consultivo de Canarias, en el Dictamen núm 1/1989, de 3 de abril, afirmó que este trámite persigue motivar una discusión «de ineliminables incidencias políticas». El Reglamento del Parlamento de Canarias, en su artículo 143.4, establece que «la audiencia a los Cabildos Insulares deberá constar entre los antecedentes de la propuesta, siempre que la iniciativa fuera del Gobierno, o recabarse en un plazo de quince días tras la toma en consideración de la misma, cuando la iniciativa fuera de la Cámara».

$2^{\circ} .^{\circ}$ Colaboran en el desarrollo y ejecución de los acuerdos adoptados por el Gobierno de Canarias [arts. 23.4, EACan, y 36.2,b), LC]. Esta colaboración se circunscribe a los acuerdos gubernamentales, y es específica (Dictamen núm. 1/1989, de 3 de abril, del Consejo Consultivo de Canarias). La responsabilidad que comporta no es originaria del Cabildo, sino derivada, en el sentido de que lo que se impone es que esos acuerdos se desarrollen y ejecuten con los contenidos y el sentido que el Gobierno de Canarias les haya dado (SARMiento Acosta) ${ }^{17}$. La previsión estatutaria es equiparable a la encomienda de la gestión ordinaria de servicios o «préstamo de órganos», ya que el Cabildo sólo actúa como un órgano de la Comunidad Autónoma.

\footnotetext{
${ }^{16}$ G. Trujillo Fernández, «La Comisión General de los Cabildos Insulares», Parlamento y Constitución, Anuario de las Cortes de Castilla-La Mancha, Universidad de Castilla-La Mancha núm. 3, 1999, pp. 45 y ss.

${ }^{17}$ Las competencias de los Cabildos Insulares, cit., pp. 105 y 106.
} 
3..$\left.^{\circ}\right)$ Asumen la representación ordinaria en cada Isla de la Administración autonómica [arts. 23.5, EACan, y 36.2,c) y 40, LC]. Es una competencia de gran calado y repercusión práctica, porque por virtud de ella el Cabildo se constituye en un agente autonómico en la Isla para el desarrollo de una serie de cometidos típicamente administrativos y de gestión que hace que sea una especie de «ventanilla» de la Administración autonómica. Por ello el artículo 40, LC, entre otras cosas, establece que los Cabildos deberán «Recibir, fechar registrar y cursar toda instancia, reclamación, recurso o documento que les fueran presentados dirigidos al Gobierno de Canarias o a su Administración Pública»; «Establecer en sus respectivas sedes una oficina de información general al público sobre la organización y actividades de las Administraciones Públicas de Canarias», o, en fin, representar «protocolariamente, a través de su Presidencia, al Gobierno de Canarias, en los actos oficiales que se celebren en la isla, salvo que asistan a los mismos su Presidente o Vicepresidente o alguno de los Consejeros del Gobierno».

4..$\left.^{\circ}\right)$ Ejecutan en nombre de la Comunidad Autónoma cualquier competencia que ésta no ejerza directamente a través de sus órganos administrativos propios (art. 23.5, EACan); lo cual constituye una cláusula residual por la cual el Cabildo ejerce cualquier competencia en nombre de la Administración autonómica cuando ésta no la ejerza. Sin embargo, esta disposición plantea un problema de gran envergadura, cual es la inseguridad jurídica, ya que no se sabe con certeza cuál es el ámbito material, el contenido, los límites y la duración de esta función residual. Es evidente que, en este contexto, el criterio rector es el de tutelar los intereses públicos y satisfacer las necesidades colectivas, para dar cumplimiento a los principios constitucionales y estatutarios (arts. 103, CE y 22.2, EACan) que informan la actuación de las Administraciones Públicas en un Estado social y democrático de Derecho (art. 1.1, CE).

5..$\left.^{\circ}\right)$ Definen o pueden definir una política económica insular, bajo la coordinación del Gobierno de Canarias (art. 15.3, EACan); competencia que deriva del papel relevante que el Cabildo asume en el contexto de las Administraciones canarias, el cual le permite, incluso, llevar a cabo una auténtica política económica insular, pero bajo la coordinación del Ejecutivo autonómico. Lo cual es completamente lógico, porque sería inadmisible que por la vía de la política económica se pudiera llevar a cabo una actividad que desconociera la unidad esencial que tiene este asunto. La «coordinación» que hay que entender en el sentido técnico, que, tanto la doctrina científica como el Tribunal Constitucional (STC núm 214/1989, de 21 de diciembre) han definido, permite ciertos poderes directivos, que puede ejercer, como es natural, el Gobierno de Canarias. 
$6^{\circ} .^{\circ} \mathrm{Y}$ todas aquellas competencias que se les transfieran o deleguen en cuanto instituciones de la Comunidad Autónoma (arts. 23.4, EACan, y 10.1, LC). Sin embargo, hay que tener presente que el artículo 10.2 LC, dice: «No serán delegables en los Cabildos funciones normativas, de planificación y coordinación en relación con competencias de carácter regional».

En el ejercicio de las citadas competencias los Cabildos actúan como instituciones de la Comunidad Autónoma de Canarias. Se observa en la definición de estas competencias concretas cómo el legislador quiere insertar las Corporaciones insulares en el entramado institucional de la Autonomía Canaria.

\section{Breve referencia de las transferencias y delegaciones}

En esta dirección, es destacable que, tanto la primera LC de 1986, como la posterior de 1990, parten de la base de que la condición institucional autonómica de las Corporaciones Insulares debe tener una manifestación clara en la faceta competencial; lo cual se ha concretado en los importantes procesos de transferencias y delegaciones que se han llevado a cabo en las últimas dos décadas. Así, con arreglo al artículo 47 de la LC de 1986, se articuló un proceso de transferencias que se concretó en los Decretos 55 a 63, de 12 de abril de 1988, sobre traspaso de funciones y servicios de la Administración Pública de la Comunidad Autónoma a los Cabildos Insulares, lo que permitió la transferencia a éstos de un importante número de materias como régimen local, policía de espectáculos, ferias y mercados insulares, artesanía, agricultura, transportes terrestres, turismo, política territorial, cultura, etc. Con la LC de 1990, se estableció, asimismo, en sus disposiciones adicionales primera y segunda, las competencias que se transfieren y delegan, respectivamente a los Cabildos, y, así, por los Decretos 150 a 159, de 21 de julio de 1994 se transfirieron a los Cabildos una serie de competencias; operación que intentó superar determinados problemas que se habían detectado, y que dieron lugar a que el propio Parlamento de Canarias aprobara en la sesión de 28 y 29 de octubre de 1992 las Resoluciones que intentaban impulsar el desarrollo y la consolidación de la LC de 1990. Y, unos años más tarde, en 1997, se aprobaron en la reunión celebrada por el Gobierno de Canarias en la Isla de El Hierro el 11 de julio de ese año, diversos Decretos de transferencias y delegaciones que comportaron un importante paso para el proceso descentralizador. Así, por virtud de los Decretos 139 a 158, de 11 de julio de 1997, se traspasaron los servicios, medios y recursos a los Cabildos para ejercer las competencias 
transferidas en una serie de materias (carreteras, transportes terrestres y por cable...); y lo que quizá, desde el punto de vista jurídico sea más importante, que en ese año de 1997 es cuando por primera vez se articula la delegación interadministrativa prevista en la LC de 1990, y se dictan los Decretos 160 a 162, la misma fecha ya indicada, los cuales permitieron la delegación en materias como servicios forestales, protección del medio ambiente y gestión y conservación de Espacios Naturales Protegidos; asistencia social y servicios sociales (atención a minusválidos y tercera edad), y carreteras de interés regional. No obstante, la articulación de este importante bloque de competencias, y, por ende, de medios, recursos y funcionarios, no ha sido ni es fácil ${ }^{18}$. Por este motivo la propia LC de 1990 ha tenido que modificarse en dos ocasiones. Una por virtud de la Ley 4/1996, de 5 de noviembre, en orden a resolver alguna cuestiones que planteaban las delegaciones; y otra por medio de la más reciente Ley 8/2001, de 3 de diciembre, para, también, solventar determinadas disfunciones técnicas y operativas que se han detectado en las delegaciones; lo que se ha hecho, según dice el Preámbulo con «la ampliación inmediata del ámbito de las transferencias competenciales operadas hasta la fecha a favor de las islas, extendiendo éstas a aquellas materias cuya delegación se habilita por la legislación vigente, y de forma inminente, a aquellas funciones cuya delegación efectiva ya ha sido acometida». Así, se establece una nueva redacción de la disposición adicional primera de la LC de 1990, y, en coherencia con ella, se han dictado varios Decretos de traspaso de funciones de la Administración Pública de la Comunidad Autónoma de Canarias a los Cabildos Insulares, como los Decretos 111 a 113, de 9 de agosto de 2002, que han realizado tales traspasos en materia de servicios forestales, vías pecuarias y pastos; protección del medio ambiente y gestión y conservación de Espacios Naturales Protegidos, servicios sociales, etc.

\section{PATRIMONIO Y FINANCIACIÓN}

Es obvio que los Cabildos, como cualquier Administración Pública, necesitan unos recursos personales, materiales y financieros para poder desempeñar sus funciones con el nivel de eficacia exigible en un Estado social y democrático de Derecho. Esta necesidad es todavía más apremiante si se repara en la circunstancia de que los Cabildos en los últimos años no han hecho otra cosa que ganar protagonismo en materia competencial,

\footnotetext{
18 M.J. Sarmiento Acosta, «Los Cabildos Insulares: notas sobre la últimas reformas», Actualidad Administrativa núm. 6, 1998, pp. 75 y ss.
} 
como ya hemos referido. Por esta razón el legislador estatutario aborda esta trascendental cuestión en dos preceptos: los artículos 48 y 50, EACan. El primero se refiere al Patrimonio insular, que está integrado por: a) El Patrimonio de la Isla a la entrada en vigor del mismo Estatuto, b) Los bienes afectos a los servicios traspasados a cada Isla, c) Los bienes y derechos que adquiera la Isla en el ejercicio de sus competencias y funciones, d) Los bienes que adquiera la isla por donación, sucesión o cualquier otro título jurídico válido, e) Cualquiera otros bienes o derechos que le correspondan a tenor de lo dispuesto en el Estatuto o por otra disposición legal. Este patrimonio debe ser gestionado, dirigido y protegido de acuerdo con los principios y prerrogativas propias de cualquier Administración Pública (arts. 41, EACan, 4.1, LRBRL, y 44 del Reglamento de Bienes de las Entidades Locales, de 13 de junio de 1986); y, por consiguiente, el Cabildo debe formular los correspondientes inventarios y catálogos, y ejercer todas las potestades administrativas encaminadas a protegerlo.

Por su parte, el artículo 50, EACan, prevé los recursos en orden a dotar a los Cabildos de una financiación definida y estable. La necesidad de tener una adecuada cobertura económica se constata en la propia Constitución Española, cuando en su artículo 142 dispone: «Las Haciendas locales deberán disponer de los medios suficientes para el desempeño de las funciones que la ley atribuye a las Corporaciones respectivas y se nutrirán fundamentalmente de tributos propios y de participación en los del Estado y de las Comunidades Autónomas»; idea que subyace, asimismo, en la Carta Europea de Autonomía Local, hecha en Estrasburgo el 15 de octubre de 1985, cuyo artículo 9 establece el derecho a unos recursos propios suficientes en el marco de la política económica nacional, la proporcionalidad de los mismos a las competencias previstas por la ley, y la exigencia de su origen al menos parcial a partir de ingresos e impuestos locales fijados por las propias Corporaciones dentro de los límites impuestos por la ley. Esta exigencia es todavía más notoria en el caso de las Corporaciones insulares, por el relevante protagonismo que en materia competencial hemos visto que asumen. Por ello el referido artículo 50 establece: «Los recursos de las Islas están constituidos por: a) Los establecidos en su legislación específica, b) Los establecidos en la legislación de régimen local, c) Los derivados del régimen económico-fiscal de Canarias, d) Las participaciones en los impuestos regionales, en las asignaciones o subvenciones estatales y en las transferencias procedentes del Fondo de Compensación Interterritorial, que puedan otorgarse por ley del Parlamento Canario, e) Los que les asignen como consecuencia de las competencias que se les transfieran». Son recursos que provienen de distintas fuentes, si bien tienen especial significación los que derivan del 
Régimen Económico y Fiscal. Así, el artículo 139, primer párrafo, de la Ley de Haciendas Locales, redactado según la modificación llevada a cabo por la reciente Ley 51/2002, de 27 de diciembre, de reforma de la Ley 39/1988, de 28 de diciembre, Reguladora de las Haciendas Locales, dice: «Las entidades locales canarias dispondrán de los recursos regulados en la presente ley sin perjuicio de las peculiaridades previstas en la legislación del régimen económico y fiscal de Canarias» ${ }^{19}$.

Por último, es claro que los Cabildos deben formar y aprobar sus propios presupuestos, y elaborar las normas reglamentarias precisas para la gestión de sus ingresos (art. 60.2, EACan.), para lo cual, como es natural, deberán someterse a las normas aplicables, y, por lo tanto, respetar las mayorías establecidas para tales casos.

\section{EL DIFÍCIL ENCAJE INSTITUCIONAL DE LOS CABILDOS EN LA AUTONOMÍA CANARIA}

La creación formal de la Comunidad Autónoma de Canarias ha supuesto una modificación de gran calado para la posición y las competencias de los Cabildos Insulares. El EACan, en su primera redacción de 1982, ya apuntaba los suficientes datos y elementos normativos para configurar un modelo de Administración Pública que descansara sobre las Corporaciones insulares, por medio de un proceso descentralizador en virtud del cual gran parte de las tareas de gestión y administración fueran desarrolladas por las mencionadas Corporaciones. Con la redacción dada al Estatuto por la Ley Orgánica 4/1996, esta orientación se consolida ya sin reservas. Los Cabildos son definidos normativamente como Corporaciones Locales y como Instituciones de la Comunidad Autónoma (arts. 8.2 y 23). Esta posición bifronte no es sino la consecuencia de «apostar» (y la palabra no se escoge por casualidad) por el régimen de Cabildos, y permitir una coexistencia de éstos con las instituciones autonómicas propiamente dichas; es decir, Parlamento, Gobierno y Presidente (art. 8.1, EACan)

Ya el legislador autonómico, tanto en la Ley 8/1986 como en la Ley 14/1990, había enfocado en esta dirección el encuadramiento de los Cabil-

\footnotetext{
${ }^{19}$ Véase la Ley 9/2003, de 3 de abril, de medidas tributarias y de financiación de las Haciendas Territoriales Canarias, que tiene por objeto la regulación del régimen de distribución de recursos derivados del Régimen Económico-Fiscal de Canarias (art. 1).

Sobre el Régimen Económico-Fiscal de Canarias, y su encuadramiento constitucional, Vid. SSTC 16/2003, de 30 de enero; 62/2003, de 27 de marzo y 72/2003, de 10 de abril; aparte de la STC $35 / 1984$, de 13 de marzo.
} 
dos en la Autonomía Canaria, permitiendo el desarrollo de unos procesos de descentralización que, sobre todo a partir de las Resoluciones del Parlamento de Canarias, de octubre de 1992, ha supuesto la transmisión de importantes competencias a estos organismos. De suerte que se puede afirmar que en Canarias el principio de descentralización se ha aplicado con resultados notables. Es probablemente una de las Comunidades en donde este principio se ha utilizado con mayor intensidad, aunque no la única. Es evidente que ello ha supuesto un esfuerzo político y administrativo colosal. A pesar de las críticas, algunas muy justificadas, otras sencillamente tendenciosas, como ocurre en tantas otras cuestiones jurídicas que están fuertemente mediatizadas por la Política, es lo cierto que lo que ha acontecido en los últimos tres lustros es trascendental; histórico podría decirse, pues marca un hito a partir del cual las Corporaciones insulares tendrán por fuerza que actuar de otra manera, con otros instrumentos y a través de otras relaciones. La imagen vetusta de Cabildos manejados con estructuras caciquiles y sometidos a los rigores de la centralización, debe pasar definitivamente a la Historia. Es verdad que también acechan nuevas amenazas, disfunciones y debilidades, pero el umbral en el cual se encuentran en la actualidad permite un remozamiento de estas ya viejas instituciones canarias.

Indudablemente, no todos los Cabildos afrontan esta nueva situación de la misma manera. Las diferencias entre unos y otros, por distintas causas que no son del caso, son notables, y obligan a reformular su funcionalidad teniendo en cuenta las características concretas de cada Cabildo. Pero lo relevante es que la articulación de este nuevo sistema dibuja un escenario que, bien definido y dirigido (correcta delimitación de las competencias, utilización de mecanismos de coordinación y cooperación, ejercicio de controles eficaces, y no sólo jurídicos, sino también políticos y sobre todo económicos, etc.), puede dar más y mejores frutos desde el punto de vista de la gestión de los intereses públicos.

En este contexto, la reforma del Estatuto de Autonomía de 1996 ha supuesto un paso también de relieve. La creación de la Comisión General de Cabildos Insulares (art. 12.3), como mecanismo de participación de los Cabildos en la actividad parlamentaria, la mejor delimitación conceptual de la Isla y del Cabildo, la nueva perspectiva con la que se plantea la organización y el funcionamiento, o, en fin, la clara reafirmación de los Cabildos Insulares como los auténticos órganos de gobierno y administración de las entidades Islas, son datos lo suficientemente reveladores de lo que se indica. Sin embargo, todavía quedan varias cuestiones pendientes para el correcto y satisfactorio encaje de los Cabildos en la Autonomía Canaria. 
La financiación adecuada al nivel de competencias, la exigencia de un mínimo de eficacia acorde con un Estado social y democrático de Derecho, la calidad de los servicios prestados por estas Corporaciones, el reciclaje del personal, la adaptación a las condiciones y particularidades de cada Isla, etc., son asuntos que todavía no acaban de estar bien resueltos, ya que a nadie se le escapa que el funcionamiento de algunos Cabildos es manifiestamente mejorable.

\section{BIBLIOGRAFÍA SUMARIA:}

Bermejo Gironés, J.I., «Los Cabildos Insulares de Canarias», Voz de la Nueva Enciclopedia Jurídica Seix, Mancomunidades de Las Palmas y Santa Cruz de Tenerife, 1952; Guimerá Peraza, M., El pleito insular (1808-1936), Santa Cruz de Tenerife,1976; Hernández BRAvo de LAGUNA, J., «La política local en Canarias: la experiencia de la Autonomía», en Jornadas sobre la situación actual de la Administración Local en Canarias, Gobierno de Canarias, 1997; Rodríguez Rodríguez, J.J., «Los Cabildos Insulares», en Instituciones de la Comunidad Autónoma de Canaria, Madrid-Barcelona, 2001; Sarmiento Acosta, M. J., Las competencias de los Cabildos Insulares, Las Palmas, 1993; «Comentarios al artículo 22», en Comentarios al Estatuto de Autonomía de Canarias, dir por J. VARona GómEZ-ACEDo, Madrid, 1996; «Reflexiones sobre la organización territorial e institucional de Canarias», en la Revista del Foro Canario, núm. 84, 1992; «El modelo territorial de Canarias ante la reforma del Estatuto de Autonomía», en Actualidad Administrativa, núm. 6, 1994 «Los Cabildos Insulares: notas sobre las últimas reformas», en Actualidad Administrativa, núm. 6, 1998; Informe sobre la organización político-administrativa de Canarias, con análisis particular de la Isla de Gran Canaria, Canarias de Derecho, Las Palmas, 1998; SuAY RINCón, J.J., «Régimen electoral. Especificidades de las Diputaciones Provinciales y Cabildos Insulares», en Estudios jurídicos y territoriales sobre Canarias, Centro de Cultura Popular Canaria, Islas Canarias, 2001; Valle Benítez, J., Los Cabildos Insulares de Canarias, Santa Cruz de Tenerife, 1970. 